\begin{tabular}{|c|c|}
\hline \multirow{3}{*}{ 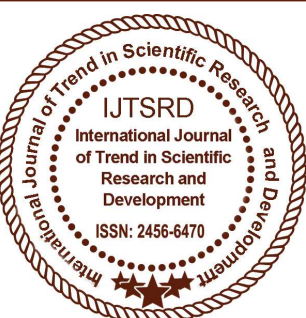 } & $\begin{array}{l}\text { International Journal of Trend in Scientific } \\
\text { Research and Development (IJTSRD) }\end{array}$ \\
\hline & International Open Access Journal \\
\hline & ISSN No: $2456-6470$ | www.ijtsrd.com | Volume - 2 | Issue -5 \\
\hline
\end{tabular}

\title{
Microstructural and Magnetic Properties of Cobalt Ferrite Nanoparticles Synthesized by Sol-Gel Technique
}

\author{
Chitra $^{1}$, T Raguram ${ }^{2}$, K S Rajni ${ }^{3}$ \\ ${ }^{1}$ Student, ${ }^{2}$ Research Scholar, ${ }^{3}$ Associate Professor \\ ${ }^{1}$ Department of Physics, Farook Arts and Science College, Kottakkal, Malappuram, Kerala, India \\ ${ }^{2,3}$ Department of Sciences, Amrita School of Engineering, Amrita Vishwa Vidyapeetham,
}

Coimbatore, Tamil Nadu, India

\section{ABSTRACT}

Cobalt ferrite ( $\mathrm{CoFe} 2 \mathrm{O} 4)$, an inverse spinal ferrite has high permeability, good saturation 1magnetization and no preferred direction of magnetization, high Curie temperature, and high electromagnetic performance. In the present work $0.2 \mathrm{M}$ cobalt nitrate $0.3 \mathrm{M}$ ferric nitrate and $0.4 \mathrm{M}$ citric acid is used to synthesis cobalt ferrite nanoparticle by sol-gel technique. As the magnetic property depends on the grain size of the synthesized nanoparticle, metal nitrate to citric acid ratio is varied from $0.8,0.6$ and 0.4 and the structural, functional morphological and magnetic characteristics are analyzed. The structural analysis shows the decrease in the average crystallite from 37 to $27 \mathrm{~nm}$ when CA/MN ratio decreases from 0.8 to 0.4 . The strain is directly proportional to dislocation density and it reflects the growth of the average grain size, and in the present study, it reflects the same. The calculated lattice parameter is found to be close to $8.373 \AA$ and the volume of the cell is found to be $5.63 \times 10-28 \mathrm{~m}$ is close to the standard value for the cobalt ferrite nanoparticles. From the EDS spectrum, the presence of $\mathrm{Co}, \mathrm{Fe}$, and $\mathrm{O}$ in the synthesized nanoparticles are noted. Functional groups analysis by FTIR shows the presence of organic sources. Surface morphology by Scanning electron microscope shows the distribution of spherical sized nanoparticles agglomerated in different sizes and the grain size calculated by image $J$ software are close to the calculated value by Scherrer formula from XRD.

Keywords: Nanoparticles, XRD, FTIR, SEM, VSM

\section{INTRODUCTION}

The materials in the nano-regime show variation in properties due to its increase in the surface area and quantum confinement effect. Due to their technological importance and in the medical field, the synthesis of magnetic nanoparticles increases the interest of the researchers. Ferrites are a ceramic compound with a spinel structure having both the property of magnetic conductor and electrical insulator and have enhanced anisotropy, high dc resistivity, and low coercivity. The applications of ferrites include photo catalysis, adsorption technologies, gas sensor, microwave devices and others [1]. Cobalt ferrite, a normal spinal ferrite has FCC structure has excellent reasonable saturation magnetization and high magneto-crystalline anisotropy [2] which are used in high density magnetic recordings, ferrofluids technology, biomedical drug delivery, magnetic resonance imaging, data storage, biosensors, and magnetooptical devices [3-5]. As the size and composition decides the properties, different synthesis methods are used which includes ceramic method by firing [6], co-precipitation [7,8], reverse micelles [9], hydrothermal $[10,11]$, using polymeric precursor[12] sol-gel technique [13], micro emulsions method [14], laser ablation technique [15], polyol method [16], sonochemical approaches [17], and aerosol method [18]. In the present work, sol-gel technique is used to synthesis cobalt ferrite nanoparticle using cobalt nitrate and ferric nitrate as a precursor and citric acid as the chelating agent. 


\section{EXPERIMENTAL}

\section{A. Cobalt Ferrite Nanoparticles Synthesis}

Cobalt ferrite nanoparticles are synthesized using citric acid as a precursor. $0.2 \mathrm{M}$ Cobalt nitrate $\left[\mathrm{Co}\left(\mathrm{NO}_{3}\right)_{2} \bullet 6 \mathrm{H}_{2} \mathrm{O}\right]$ and $0.2 \mathrm{M}$ ferric nitrate $\left[\mathrm{Fe}\left(\mathrm{NO}_{3}\right)_{3} \cdot 9 \mathrm{H}_{2} \mathrm{O}\right]$ and $0.4 \mathrm{M}$ citric acid $\left[\mathrm{C}_{7} \mathrm{H}_{8} \mathrm{O}_{7} \cdot \mathrm{H}_{2} \mathrm{O}\right]$ is prepared in distilled water and the concentration of citric acid (CA) to metal nitrate $(\mathrm{MN})$ solution is taken as $0.8,0.6$ and 0.4 . The $\mathrm{pH}$ of the solution is maintained at 8 . The mixed solution is then heated to $80{ }^{\circ} \mathrm{C}$ with constant stirring for two hours till a brown gel is obtained. The gel is heated to $800{ }^{\circ} \mathrm{C}$ for three hours to remove excess of water. During the process of drying, the gel swells into a fluffy mass and eventually broke into brittle flakes.

\section{B. Characterisation}

The samples were subjected to Powder X-ray diffraction analysis using Shimadzu XRD 6000 diffractometer with $\mathrm{CuK \alpha}$ radiation of wavelength $1.541 \AA$. The functional group is analyzed by FTIR using Perkin-Elmer spectrometer by $\mathrm{KBr}$ pellet technique in the range of $4000-400 \mathrm{~cm}^{-1}$. The morphology analysis is assessed by Scanning Electron microscopy using JEOL (JSM 6390). Magnetic properties of the samples are analyzed by VSM (Model 7407) at room temperature with the maximum applied field of $15 \mathrm{kOe}$.

The crystallite size (D) is calculated using the Scherrer formula [19] from the full- width half maximum (FWHM) $(\beta)$ for the most intense peak (311)

$\mathrm{D}=(\mathrm{k} \lambda) /(\beta \cos \theta) \AA$

Miller indices $(\mathrm{h}, \mathrm{k}, \mathrm{l})$ are related to inter-atomic spacing (d) spacing and for cubic crystals, the lattice parameter ' $a$ ' is calculated for prominent peak (311) using the relation [20]

$\mathrm{a}=\mathrm{dhkl} /\left(\mathrm{h}^{2}+\mathrm{k}^{2}+\mathrm{l}^{2}\right)^{1 / 2} \AA$

The strain $(\varepsilon)$ is calculated from the relation with $\beta$ $\varepsilon=\beta \cos \theta / 4$

The dislocation density $(\rho)$ is defined as the length of dislocation lines per unit volume of the crystal, is calculated from the formula

$\rho=1 / \mathrm{D}^{2}$ lines $/ \mathrm{cm}^{3}$

The theoretical X-ray density, ( $\rho x)$ is calculated by the relation [20]

$\rho \mathrm{x}=8 \mathrm{M} / \mathrm{Na}^{3} \mathrm{~g} / \mathrm{cm}^{3}$
Where $\mathrm{M}$ is the molecular weight of the sample and $\mathrm{A}$ is the Avogadro's number $\left(6.022 \times 10^{23} \mathrm{~mol}^{-1}\right)$ and ' $\mathrm{a}$ ' is the lattice parameter

The X-ray diffraction data is used to calculate ionic radii $(\mathrm{rA}, \mathrm{rB})$ and bond lengths $(\mathrm{A}-\mathrm{O}),(\mathrm{B}-\mathrm{O})$ at the tetrahedral and octahedral sites, is given by the equations.
$\mathrm{rA}=(\mathrm{u}-1 / 4) \mathrm{a} \sqrt{3}-\mathrm{r}\left(\mathrm{O}^{-2}\right) \AA$
$\mathrm{rB}=(5 / 8-\mathrm{u}) \mathrm{a}-\mathrm{r}\left(\mathrm{O}^{-2}\right) \AA$
$\mathrm{A}-\mathrm{O}=(\mathrm{u}-1 / 4) \mathrm{a} \sqrt{3} \AA$
$\mathrm{B}-\mathrm{O}=(5 / 8-\mathrm{u}) \mathrm{a} \AA$

Where ' $a$ ' is the lattice constant; $r\left(\mathrm{O}^{-2}\right)$ is the radius of oxygen ion (1.35 $\AA$ ); $\mathrm{u}$ is the oxygen ion parameter and for ideal spinel ferrite $u=3 / 8$.

Hopping lengths at tetrahedral sites (LA) and at octahedral sites (Lв) which is the distance between the magnetic ions is calculated by the following equation

$\mathrm{LA}=\mathrm{a}(\sqrt{3} / 4) \AA$

$\mathrm{LB}=\mathrm{a}(\sqrt{2} / 4) \AA$

\section{RESULTS AND DISCUSSION}

All paragraphs must be indented. All paragraphs must be justified, i.e. both left-justified and rightjustified.

\section{A. Structural Analysis}

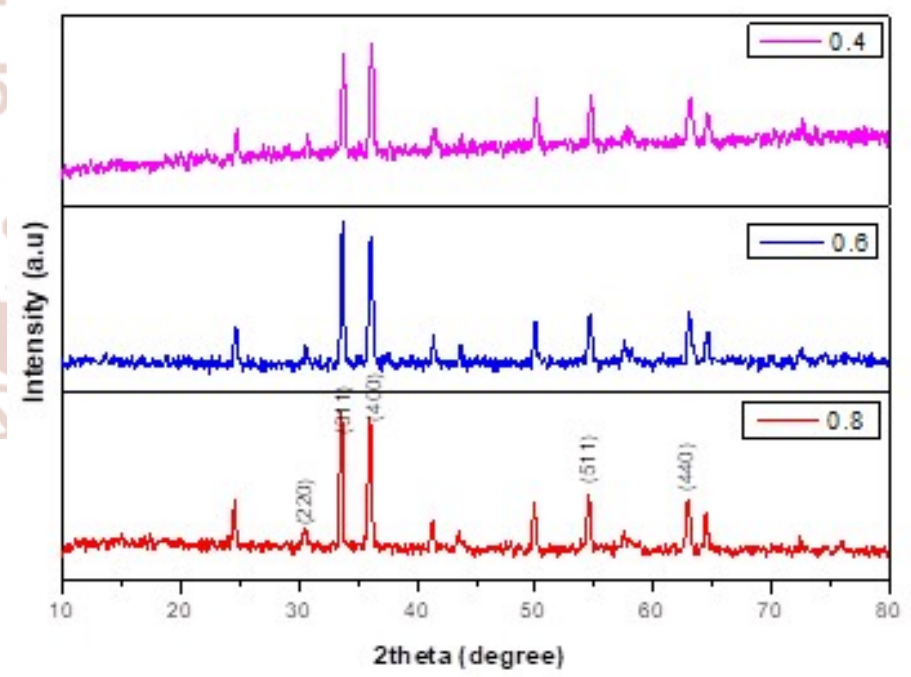

Fig. 1 PXRD Pattern of cobalt ferrite nanoparticle with different $\mathrm{CA} / \mathrm{MN}$ ratio

The Structural studies are carried out and PXRD pattern as shown in the fig.1. The observed peaks (220), (311), (400), (440) and (511) matches well with the JCPDS data of cobalt ferrite nanoparticle [21]. It is noted that the slight decrease in the intensity of the plane corresponding to (311) compared to (400) plane 
is observed when the $\mathrm{CA} / \mathrm{MN}$ ratio decreases from 0.8 to0.4. The microstructural parameters of cobalt ferrite nanoparticle are shown in table 1 . It is noted that the grain size varies from 37 to $27 \mathrm{~nm}$ as the ratio of $\mathrm{CA} / \mathrm{MN}$ decreases from 0.8 to 0.4 is attributed to the burning of nitrates due the higher volume and concentration of the chelating agent. The variation in the strain and the dislocation density with respect to crystallite size. Fig. 2 shows the lattice constant and X-ray density varies with crystallite size. The observed lattice constant is found to be less than the value for the bulk $(8.373 \AA)$ is attributed to the nanosizing effect. It is noted that the lattice constant decreases from 8.314 to 8.170 when $\mathrm{CA} / \mathrm{MN}$ decreases from 0.8 to 0.4 . The calculated volume of the cell is less compared to the bulk value $\left(590.99 \mathrm{~A}^{\circ}\right)$ is attributed to the nanosizing effect in cobalt ferrite nanoparticles [22]. X-ray density found to increase with a decrease in the lattice constant and similar type of observations are noted for $\mathrm{Mg}-\mathrm{Zn}$ ferrite system prepared at different molar concentrations [23]. Also, the value of the X-ray density is higher than their bulk value is due to the formation of pores during the synthesis process and due to the ionic radii $[13,24]$. The mean ionic radius of octahedral site $\mathrm{B}(\mathrm{rB})$ is found to decrease slowly than the tetrahedral site A (rA). A similar type of observations is noted by other investigators for their Co-Zn system [25]. The hopping length LA and LB, bond length A-O and B-O decrease gradually with the decrease in the CA/MN ratio and the crystallite size which reflects the decrease in lattice constant which is shown in the table 1 .

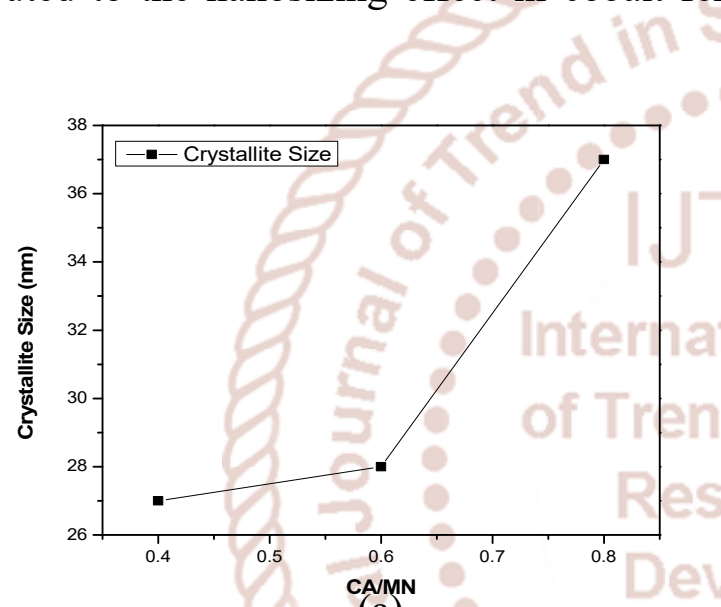

(a)

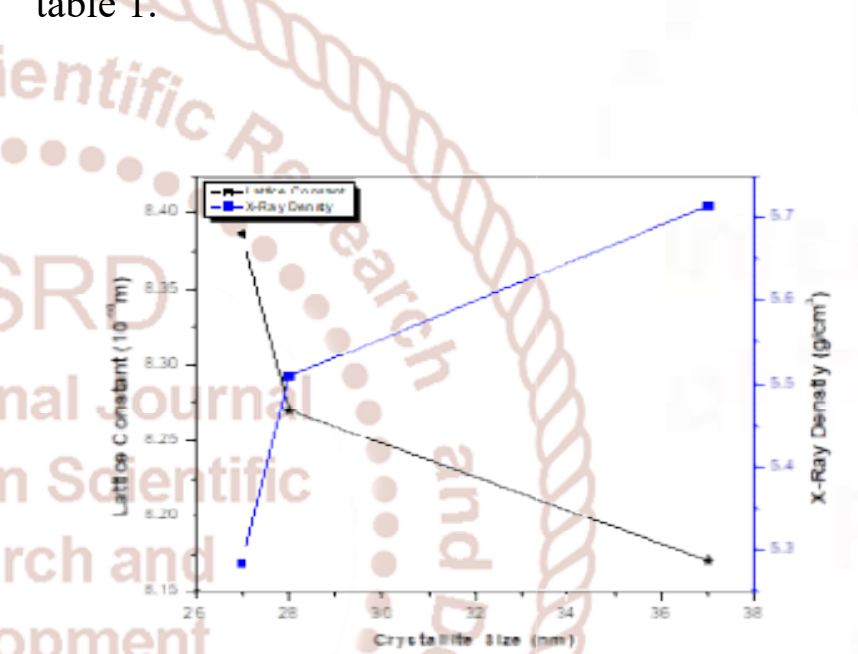

(b)

Fig. 2 Structural analysis of cobalt ferrite nanoparticles with different $\mathrm{CA} / \mathrm{MN}$ ratio

a) Crystallite size Vs CA/MN ratio b) Lattice constants, X-Ray Density Vs Crystallite size ratio

Table I Hopping Length, Bond Length and Radius of The Ions at The Tetrahedral and Octahedral Sites of Cobalt Ferrite Nanoparticles

\begin{tabular}{|c|c|c|c|c|c|c|}
\hline $\mathbf{C A} / \mathbf{M N}$ & $\mathrm{L}_{\mathbf{A}}\left(\mathbf{A}^{\circ}\right)$ & $\mathrm{L}_{\mathbf{B}}\left(\mathbf{A}^{\circ}\right)$ & $\mathbf{A}-\mathbf{O}\left(\mathbf{A}^{\circ}\right)$ & $\mathbf{B}-\mathbf{O}\left(\mathbf{A}^{\circ}\right)$ & $\left(\mathrm{r}_{\mathbf{A}}\right)\left(\mathbf{x} 10^{-11} \mathbf{m}\right)$ & $\left(\mathbf{r}_{\mathbf{B}}\right)\left(\mathbf{x} 10^{-11} \mathbf{m}\right)$ \\
\hline 0.8 & 3.0991 & 2.9218 & 1.7892 & 2.0660 & 4.3927 & 7.1607 \\
\hline 0.6 & 3.0932 & 2.9163 & 1.7858 & 2.0621 & 4.3587 & 7.1214 \\
\hline 0.4 & 3.0878 & 2.9112 & 1.7827 & 2.0585 & 4.3277 & 7.0856 \\
\hline
\end{tabular}

\section{B. Functional Group Analysis}

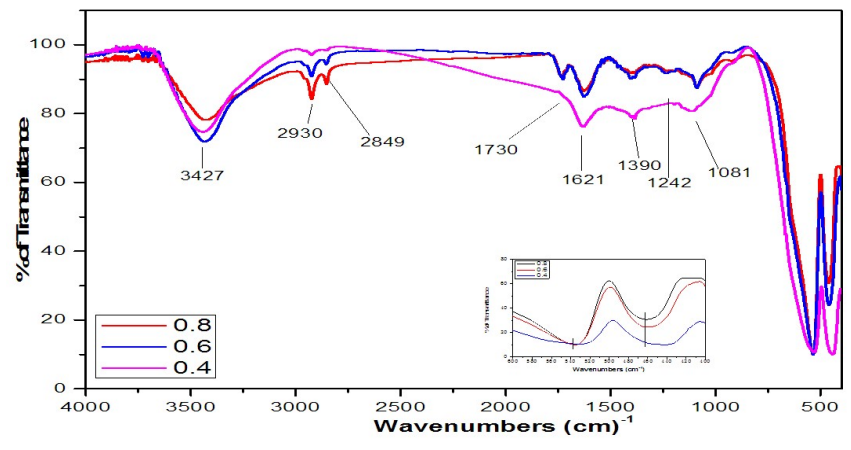

Fig.3 Structural analysis of cobalt ferrite nanoparticles with different $\mathrm{CA} / \mathrm{MN}$ ratio. a) Crystallite size Vs CA/MN ratio. b) Lattice constants, X-Ray Density Vs Crystallite size ratio

Fig. 3 shows the FTIR Spectra of the prepared samples. The peak positions of the functional groups are listed in table 2. It is noted that Nitrate group has six normal vibrations that are IR active and found in IR spectra. They are (i) anti-symmetric stretching 
(1629 cm-1),(ii) symmetric stretching (1388 cm1),(iii) totally symmetric stretching $(1052 \mathrm{~cm}-1)$,(iv) out of plane bending $(870 \mathrm{~cm}-1),(\mathrm{v})$ anti-symmetric in-plane bending $(729 \mathrm{~cm}-1)$,(vi) symmetric in-plane bending $(664 \mathrm{~cm}-1)$. From the spectra, it is noted that the peak observed at $600 \mathrm{~cm}-1$ corresponds to characteristic stretching of $\mathrm{Fe}-\mathrm{O}[26]$. The peaks corresponds to organic sources are also exists in the compound which is observed in the XRD. The peak positions of the functional groups are listed in the table and the presence of organic sources that exists in the compound can be removed by annealing the samples at suitable temperature and duration.

TABLE II FT-IR Peak positions of cobalt ferrite nanoparticles

\begin{tabular}{|c|c|c|c|}
\hline \multicolumn{3}{|c|}{ Wavenumbers $\left(\mathrm{cm}^{-1}\right)$} & \multirow[t]{2}{*}{ Spectral Assignments } \\
\hline 0.8 & 0.6 & 0.4 & \\
\hline 3428.92 & 3436.43 & 3435.64 & stretching vibrations of free and absorbed water[28] \\
\hline 2923.44 & 2923.31 & 2923.14 & $\begin{array}{c}\text { axial deformation of } \\
\text { C-H bond (antisymmetric and symmetric stretching) }[31]\end{array}$ \\
\hline 2849 & 2849 & 2849 & $\begin{array}{c}\text { axial deformation of } \\
\mathrm{C}-\mathrm{H} \text { bond(antisymmetric and symmetric stretching)[31] }\end{array}$ \\
\hline 1730 & 1730 & - & $\mathrm{C}=\mathrm{C}$ vibrations \\
\hline 1625.98 & 1626.33 & 1611.80 & H-OH bending of water molecule $[28,29]$ \\
\hline 1390.82 & 1382.28 & 1383.46 & symmetric stretching \\
\hline 1242 & 1242 & -2 & Nitrate anion overlap with vibrations of C-H [30] \\
\hline 1081 & 1081 & 1081 & 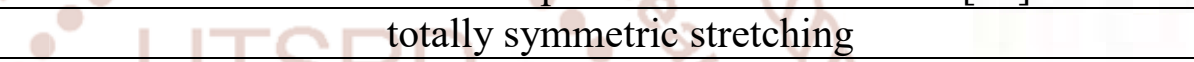 \\
\hline 595.62 & 587.67 & 584.96 & $\begin{array}{l}\text { Intrinsic stretching vibration of bond between oxygen and tetrahedral } \\
\text { metal ion } \mathrm{M}_{\text {tetra } \leftrightarrow \text { O }} \text { [32] }\end{array}$ \\
\hline 461.105 & 457.884 & 438.221 & Internationoctahedral metal stretching[32] \\
\hline
\end{tabular}

\section{Morphological Analysis}

The scanning electron microscopic images of the synthesized samples are shown in Fig. 4. It is evident that the SEM images show a uniform distribution of grain with agglomeration in the nanometric region confirming the crystalline nature of the particle. It is also noted that at higher CA/MN ratio, pores are noted which is due to the gas evolution during the synthesis process at a higher temperature. The grain size calculated by image $\mathrm{J}$ software is found to be close with the grain size calculated from Scherrer formula form XRD.

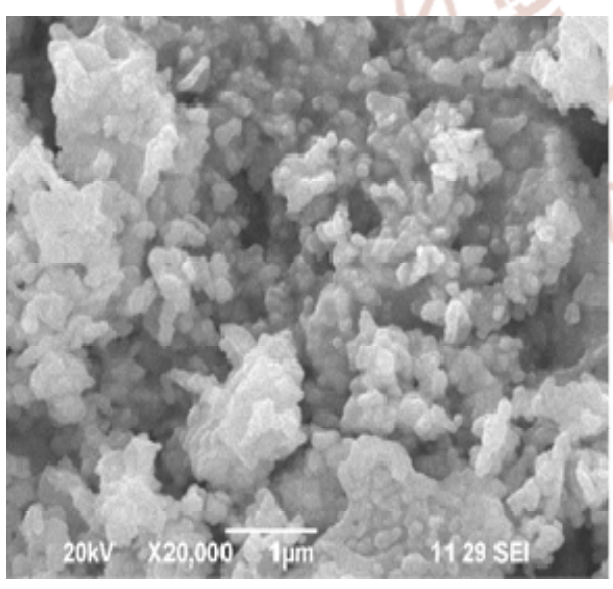

(a) $\mathrm{CA} / \mathrm{MN}=0.8$

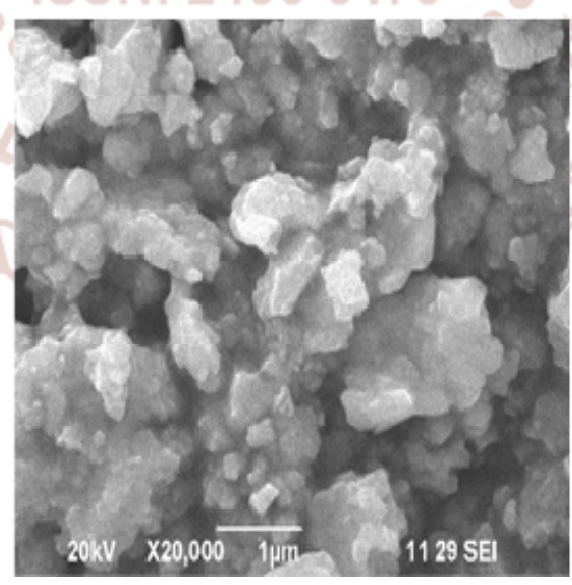

(b) $\mathrm{CA} / \mathrm{MN}=0.6$

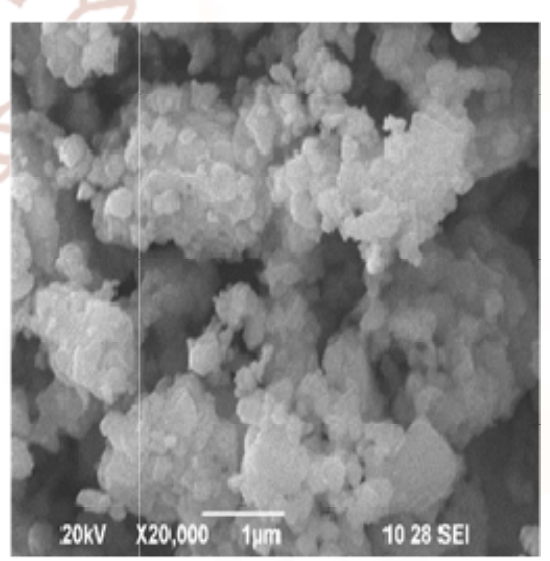

(c) $\mathrm{CA} / \mathrm{MN}=0.4$

Fig. 4 Morphological analysis of cobalt ferrite nanoparticles with different $\mathrm{CA} / \mathrm{MN}$ ratio 


\section{Compositional Analysis}

Fig. 5 shows the compositional analysis by Energy dispersive X-ray spectroscopic (EDS). The analyses indicate the synthesized sample is $\mathrm{CoFe}_{2} \mathrm{O}_{4}$ and the atomic ration of $\mathrm{Co}: \mathrm{Fe}: \mathrm{O}$ is close to that of $\mathrm{CoFe}_{2} \mathrm{O}_{4}$ formula. The atomic weight $(\%)$ of the prepared samples are shown in the fig. 6 .

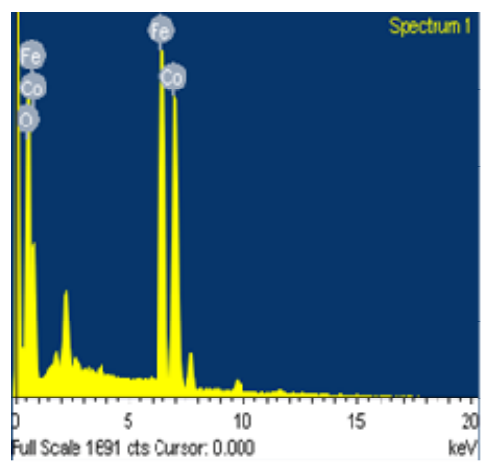

(a)

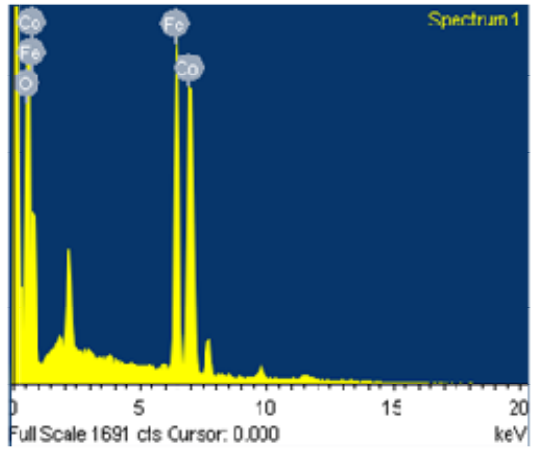

(b)

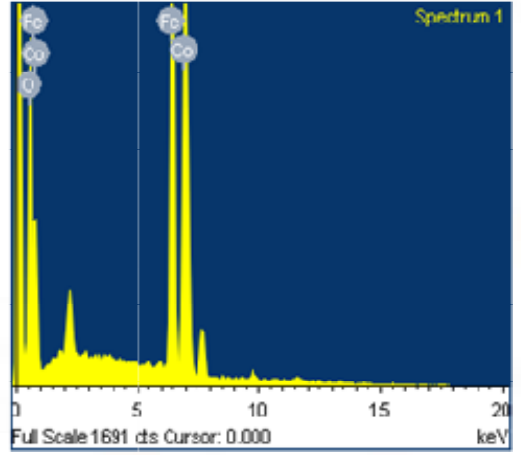

(c)

Fig. 5 Compositional analysis of cobalt ferrite nanoparticle with different $\mathrm{CA} / \mathrm{MN}$ ratio

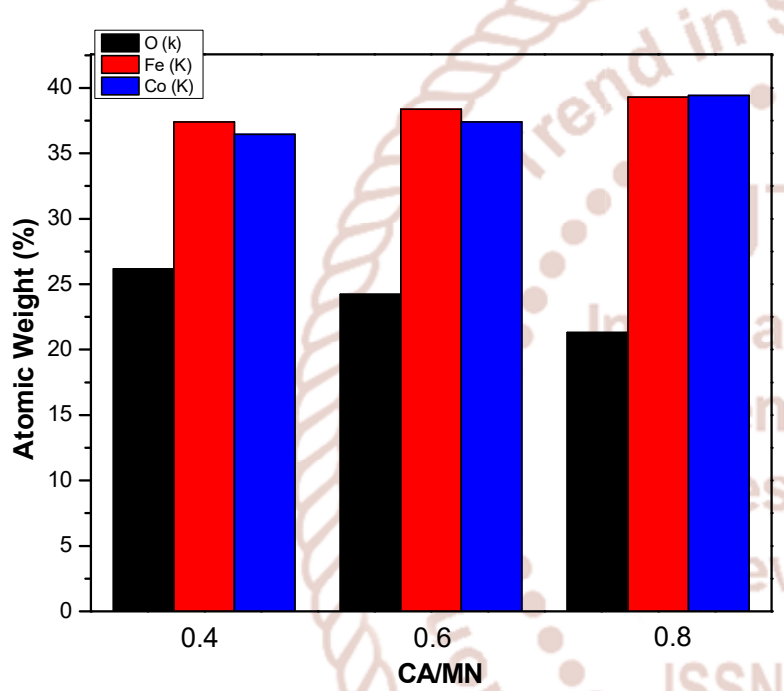

Fig. 6 Atomic Weight (\%) of cobalt ferrite nanoparticle with different $\mathrm{CA} / \mathrm{MN}$ ratio

\section{E. VSM Analysis}

The magnetic parameters are analyzed by vibrating sample magnetometer (VSM) with a maximum field of $15 \mathrm{kOe}$ at room temperature. The magnetic properties of cobalt ferrite nanoparticles are decided by cation distribution, size and the synthesis procedure $[19,20]$ and these properties are explained on the basis of the surface disorder. The random distribution of cation and the canted spin structure results in surface disorder. Also, broken exchange bonds and high anisotropy on the surface leads to surface disorder $[27,28]$. In the case of cobalt ferrite nanoparticle $\mathrm{Co}^{2+}$ ion arbitrarily occupy both tetrahedral (A) site and octahedral (B) sites, so some of the $\mathrm{Fe}^{3+}$ ion $(0.645 \AA)$ move to octahedral site to replace heavier $\mathrm{Co}^{2+}$ ion $(0.72 \AA)$ [29-31].The migration of $\mathrm{Fe} 3+$ ion to $\mathrm{B}$ site results in compressive strain as the distance between the B site is smaller than the A site. This compressive strain leads to the breaking of surface exchange bonds which results in canted spin structure. This kind of structure weakens $\mathrm{AA}, \mathrm{BB}$ and $\mathrm{AB}$ interactions which results in low magnetization values at room temperature compared to the bulk cobalt ferrite particle [32]. Fig. 7 (a) and (b) shows the VSM analysis and Coercivity and Saturation Magnetization varies with the crystallite size. It is noted that the coercivity and saturation magnetization increases with the decrease in the average crystallite size and $\mathrm{CA} / \mathrm{MN}$ ratio. The coercivity increase from 36 to 112 when the crystallite size decreases from 38 to $27 \mathrm{~nm}$. The decrease in coercivity is due to the expected crossover from a single domain to multidomain as particle size increases from 27 to $38 \mathrm{~nm}$ [33]. The existence of the superparamagnetic behaviour of the synthesised particle is attributed to the finite crystallite size and the shape of the material [34]. The saturation magnetisation is found to be lesser than the saturation magnetisation for bulk ( $80 \mathrm{emu} / \mathrm{g})$ is attributed to the surface defects and morphology [35]. The surface defects are due to the finite crystallite size which leads to the non-collinear magnetic moments on the surface of the nanoparticle. These type of defects are intense in the ferromagnetic system and the superexchange interaction occurs through the oxygen ion [36].

The experimental magnetic moment $(\eta \mathrm{B})$ is calculated by the relation [37]

$\eta \mathrm{B}=\mathrm{MMS} / 5585$

Where $\mathrm{M}$ is the molecular weight. 
The anisotropy constant is evaluated using following relation [38]

$\mathrm{Hc}=0.96 \mathrm{~K} / \mathrm{MS}$, Where $\mathrm{K}$ is anisotropy constant

Table 3 shows the variation of magnetic moment, remanence ratio and anisotropic constant of the cobalt ferrite nanoparticle. The variation of magnetic moment with grain size can be explained on the basis of cation distribution and the strength of the superexchange interaction between the ions on the tetrahedral (A) and octahedral (B) sublattices. The remanence ratio $\mathrm{Mr} / \mathrm{Ms}$ is the characteristic parameter of magnetic materials and provides information by which the direction of magnetization reorients to the nearest easy axis magnetization direction after the magnetic field switch off [39].

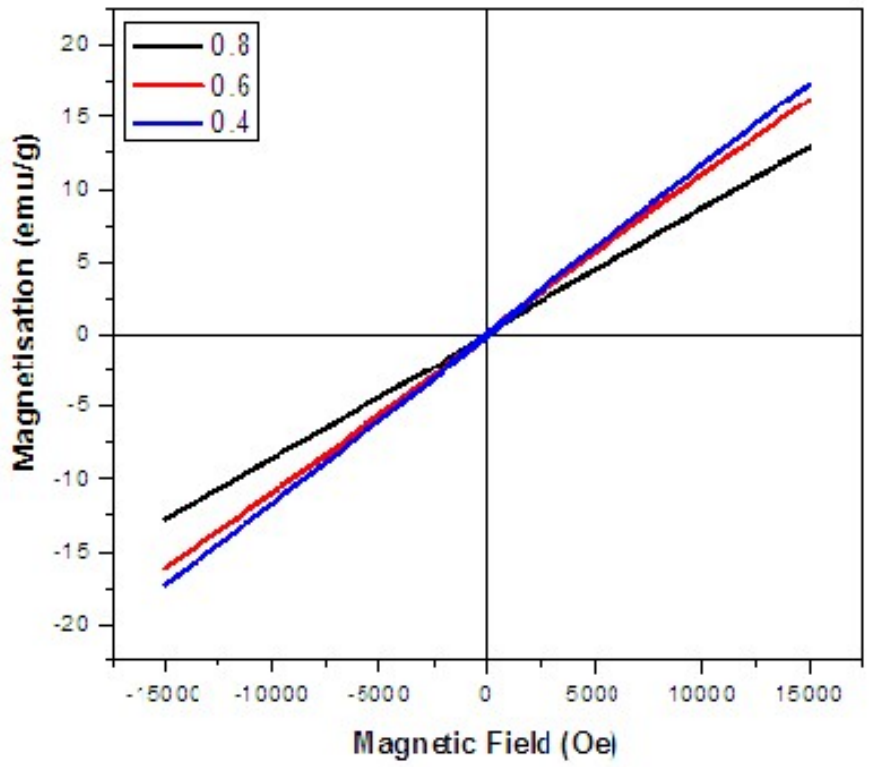

a)

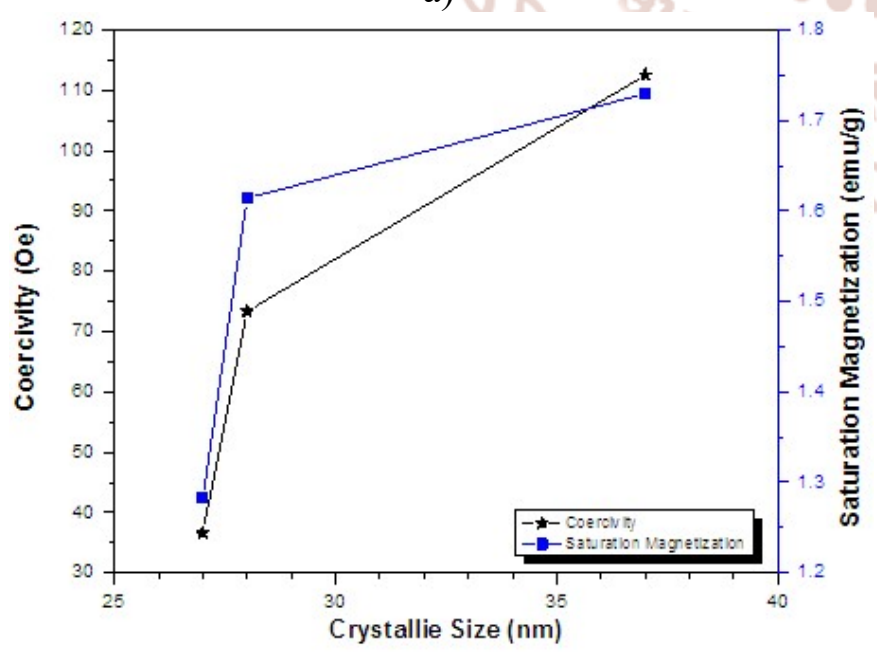

b)

Fig. 6: Magnetic Analysis. a) Magnetization Vs Magnetic field and b) Coercivity, Saturation Magnetization Vs Crystallite Size
Table III Magnetic Moment, Anisotropic Constant and Remenance Ratio Ofcobalt Ferrite Nanoparticles

\begin{tabular}{|c|c|c|c|}
\hline CA/MN & $\begin{array}{c}\text { Magnetic } \\
\text { moment } \\
\left(\mathbf{n}_{\mathrm{B}}\right)\end{array}$ & $\begin{array}{c}\text { Anisotropic } \\
\text { constant(K) }\end{array}$ & $\mathbf{M}_{\mathbf{r}} / \mathbf{M}_{\mathrm{s}}$ \\
\hline 0.8 & 0.0538 & 48.81 & 3.2183 \\
\hline 0.6 & 0.0667 & 123.34 & 5.6113 \\
\hline 0.4 & 0.0726 & 202.84 & 7.8990 \\
\hline
\end{tabular}

\section{CONCLUSIONS}

Cobalt ferrite, a hard magnetic, inverse spinal ferrite is synthesized by a sol-gel technique using citric acid as the chelating agent. Structural analysis shows the observed peak matches with the standard data. Also, peaks corresponding to $\mathrm{FeO}(\mathrm{OH}), \alpha-\mathrm{Fe} 2 \mathrm{O} 3$ are observed. The average crystallite size was found to be 35 to $27 \mathrm{~nm}$ when $\mathrm{CA} / \mathrm{MN}$ ration decreases from 0.8 to 0.4 . Functional group analysis shows the presence of the organic sources which can be removed by annealing. SEM analysis shows more pores in the synthesized nanoparticle which is attributed to the gas evolved during the synthesis process at a higher temperature. a From the VSM analysis, the paramagnetic behavior of the synthesized nanoparticles are noted. The magnetic parameters such as coercivity, remanence, and saturation magnetization increases with the decrease in the crystallite size which is due to the surface disorder.

\section{REFERENCES}

1. K. Praveena, K. Sadhana, S. Bharadwaj and S. R. Murthy, J. Magn. Magn. Mater. 3208433 (2009)

2. Yue Zhang, Zhi Yang, Di Yin, Yong Liu and Chun Long Fei, J. Magn. Magn. Mater, 3223470 (2010)

3. E. Veena Gopalan, P. A. Joy, I. A Al-Omari, D Sakthi Kumar, Yasuhiko Yoshida, and M. R. Anantharaman, J. Alloys compd 485711 (2009)

4. Mathew George, Asha Mary John, Swapna S Nair, P. A. Joy and M. R. Anantharaman, Journal of Magnetism and Magnetic Materials 302190 (2006)

5. C. N. Chinnasamy, M. Senoue, B. Jeyadevan, Oscar Perales-Perez, K. Shinoda, K. Tohji, Journal of Colloidal Interface Science 26383 (2003)

6. M. H. Khedr, A. A. Omar and S. A. Abdel-Moaty, Colloids and Surfaces A 2818 (2006) 
International Journal of Trend in Scientific Research and Development (IJTSRD) ISSN: 2456-6470

7. J. B. Silva, W. De. Brito and N. D. S. Mohallem, Materials Science and Engineering B 112182 (2004)

8. Z. Zi, Y. Sun, X. Zhu, Z. Yang, J. Dai and W. Song, Journal of Magnetism and Magnetic Materials 3211251 (2009)

9. L. Calero-DdelC and C. Rinaldi, Journal of Magnetism and Magnetic Materials 31460 (2007)

10. D. Zhao, X. Wu, H. Guan and E. Han, Journal of Supercritical Fluids 42226 (2007)

11. L. Chen, Y. Shen and J. Bai, Materials Letters 63 1099 (2009)

12. M. Gharagozlou, Journal of Alloys and Compounds 486660 (2009)

13. H. Gul and A. Maqsood, Journal of Alloys and Compounds 465227 (2008)

14. Pillai and D. O. Shah, Journal of Magnetism and Magnetic Materials 1631243 (1996)

15. J. Zhang and C. Q. Lan, Materials Letters 621521 (2008)

16. G. Baldi, D. Bonacchi, C. Innocenti, G. Lorenzi and C. Sangregorio, Journal of Magnetism and Magnetic Materials 31110 (2007)

17. K. V. P. M. Shafi, A. Gedanken, R. Prozorov and J. Balogh, Chemistry of Materials 103445 (1998)

18. Singhal, J. Singh, S. K. Barthwal and K. Chandra, Journal of Solid State Chemistry 1783183 (2005)

19. B. D. Cullity, Elements of X-Ray Diffraction (Addison - Wesley Publishing Company Inc) (1956)

20. J. Smith and H. P. J. Wijn, Ferrites (Philips Technical Library, Eindhoven, 150) (1959)

21. S. Pauline and Persis Amaliya, Archives of Applied Science Research 3213 (2011)

22. Anal K. Jha (and Kamal Prasad Nanotechnology Development 2:e (2012)

23. Pandit A. Shitre R, D. R. Shengule, K. M. Jadhav, J. Mater. Sci. 40423 (2005)
24. M. U. Abbas T Islam and Ch. M. Ashraf, Modern Phys. Lett. B 91419 (1995)

25. N. M. Deraz and A. Alarifi, J. Anal. Appl .Pyrolysis 9755 (2012)

26. N. Zotov, K. Petrov and M Dimitrova Pankova, J. Phys. Chem. Solids 511199 (1990)

27. B. D. Cullity, "Elements of X-Ray Diffraction", Addison - Wesley Publishing Company Inc (1956)

28. Smit, J. and Wijn, H. P. J. (1959) Ferrites. Philips Technical Library, Eindhoven, 150.

29. M. Younas, M. Nadeem, M. Atif and R. Grossinger, J. Appl. Phys. 109093704 (2011)

30. J. Jacob and M. A. Khadar, J. Appl. Phys. 107 $114310(2010)$

31. Atta ur Rahman, M. A. Rafiq, K. Maaz, S. Karim, Sung Oh Cho and M. M. Hasan, Journal of Applied Physics 112063718 (2012)

32. Franco Jr. and F. C. Silva, Journal of Applied Physics 113 17b513 (2013)

33. C. Nlebedim, R. L. Hadimani, R. Prozorov and D. C. Jiles, Journal of Applied Physics 113 17A928 (2013)

34. M. Younas, M. Nadeem, M. Atif, and R. Grossinger, J. Appl. Phys. 109093704 (2011)

35. Q. Chen and Z. Zang, J. Appl. Phys. Lett. 733156 (1998)

36. R. B. Kamble, V. Varade, K. P. Ramesh and V. Prasad, AIP Adv. 5017119 (2015)

37. S. Roy and J. Ghose, J. Appl. Phys. 876226 (2000)

38. C. Caizer and Stefanescu, J. Phys. D: Appl. Phys. 353035 (2002)

39. D. S. Nikam, S. V. Jadhav, V. M. Khot, R. A. Bohara, C. K. Hong, S. S. Mali and S. H. Pawar, RSC Adv. 52338 (2015) 